\title{
Agricultural Pesticides and Risk of Childhood Cancers
}

\author{
Susan E. Carozza ${ }^{1}$, Bo Li ${ }^{2}$, Qing Wang ${ }^{3}$, Scott Horel ${ }^{1}$, and Sharon Cooper ${ }^{4}$ \\ 1 Department of Epidemiology \& Biostatistics, TAMU HSC School of Rural Public Health, College Station, \\ TX 77843-1266, scarozza@srph.tamhsc.edu, phone: 979 862-8168, fax: $979458-1877$
}

2 National Center for Atmospheric Research, 1850 Table Mesa Drive, Boulder, CO 80307-3000

3 Department of Statistics, Texas A\&M University, College Station, TX 77843

4 UT-Houston School of Public Health, San Antonio Regional Campus, 7703 Floyd Curl Drive, MC 7976, San Antonio, TX 78284-7976

\begin{abstract}
Agricultural pesticide applications have the potential for significant drift beyond the target spray area and may result in exposure to non-farming residents in surrounding communities. Using geographic information system (GIS) methods, 1778 childhood cancer cases and 1802 controls born in Texas between 1990 and 1998 were assigned probable agricultural pesticide exposure based on proximity of birth residence to crop fields. Multivariate modeling was used to estimate odds ratios and 95 percent confidence intervals for selected cancers. For most childhood cancers, we found no evidence of elevated risk associated with residential proximity at birth to cropland. There was an overall pattern of increased risk for germ cell tumors but the odds ratios were based on few numbers of exposed cases. There was also some indication of increased risk for NHL and Burkitt lymphoma, but point estimates were imprecise and not statistically significant. Previous studies have assessed pesticide exposure primarily based on parental occupational history or household use, while our focus was on agricultural pesticides and so may represent a different array of chemical agents occurring at lower doses.
\end{abstract}

\section{Keywords}

agriculture; pesticides; childhood cancers; epidemiology

\section{Introduction}

The etiology of childhood cancers remains largely a mystery, leaving few avenues for prevention. Whether environmental exposures, such as commonly used pesticides, may have a role in the initiation and/or development of childhood cancers continues to be of interest and concern. There are a variety of mechanisms by which pesticides may potentially initiate or promote cancer, including mutagenicity, tumor promotion, immunotoxicity and hormonal disruption (Dich et al., 1997).

\footnotetext{
Correspondence to: Susan E. Carozza.
}

Publisher's Disclaimer: This is a PDF file of an unedited manuscript that has been accepted for publication. As a service to our customers we are providing this early version of the manuscript. The manuscript will undergo copyediting, typesetting, and review of the resulting proof before it is published in its final citable form. Please note that during the production process errors may be discovered which could affect the content, and all legal disclaimers that apply to the journal pertain. 
Pesticides are used in great quantities in both rural and urban U.S. communities, and recent surveys have found exposure to some mix of pesticides to be almost ubiquitous among the U.S. population (CDC 2005;Fenske et al., 2002;Lu et al., 2001). Pesticide applications in agricultural settings have the potential for significant drift beyond the target spray area. Depending on particle size, humidity and wind conditions, aerially applied pesticides can drift for miles (Tiefenbacher 1998; van den Berg et al., 1999) and measurable amounts of metabolites of agricultural pesticides have been reported in non-farming households and communities (Baker et al., 1996;CDC 2005;Koch et al., 2002;Shalat et al., 2003). Children in these communities may be more vulnerable than adults both for potential pesticide exposure, because of age-related behaviors such as mouthing objects and crawling, and for exposure effects, because of their small body mass relative to dose.

Texas is one of the leading agricultural producers in the United States. Recent agricultural surveys indicate that all but one of the five top crops by acreage in Texas was treated with chemicals that show evidence of possible human carcinogenicity (USDA 1997; USEPA 2004). Many of these crops are sprayed from crop dusting airplanes, increasing the potential for off-target drift. The goal of this epidemiological case-control study was to estimate the risk of developing specific childhood cancers associated with prenatal exposure to pesticides used in agricultural settings in Texas.

\section{Materials and methods}

\section{Study subjects}

This study is based on a sub-set of data from an ongoing case-control study of agricultural pesticides and risk of childhood cancers. Initially, Texas children born between 1975 and 1998 and less than age 15 years at diagnosis who were reported to the Texas Cancer Registry (TCR) were eligible for inclusion in the parent study. The TCR data represent statewide, populationbased cancer incidence among children in Texas. The TCR identified a total of 4,737 childhood cancer cases meeting these criteria. Due to restrictions in availability of imagery necessary for exposure assessment, for the present study we restricted cases to those children with a conception date on or after January 1, 1990 (calculated as nine months prior to the birth date), resulting in a total of 2,053 eligible cases ages 0 to 8 years old.

For the original study, an equivalent number of controls $(n=4,737)$ were randomly selected from among Texas births from 1975 to 1998 and frequency matched to cases on birth date and gender. Birth records of known cases were excluded and controls were selected only from among children born with no known malformations. Using the criteria of a calculated conception date on or after January 1, 1990 resulted in a total of 2,059 eligible controls for the current study.

Cases and controls were linked to the Texas Department of State Health Services (DSHS) Vital Statistics birth certificate data files to determine maternal residence at birth as well as to collect information on potential confounders, including child's age at diagnosis, gender, race/ ethnicity, maternal age, birth weight, maternal smoking and alcohol use, and maternal and paternal education level and occupation.

Human subjects approval for this study was granted by the Texas DSHS and the Texas A\&M University human subjects review boards.

\section{Development of study geographic information system (GIS)}

Residence at birth for each study subject, as captured from the DSHS birth certificate files, was assigned latitude and longitude coordinates (i.e. geocoded) using Centrus Desktop and DeLorme Street Atlas software. A total of 1778 cases (86.6\%) and 1802 controls (87.5\%) were 
successfully geocoded. Reasons for unsuccessful geocoding of study subjects included: no address included on birth certificate (1.2\%); post office box given as address (2.7\%); rural route given rather than specific address (5.0\%); no street number included (1.9\%); address not found in street data file (2.2\%). There was no significant difference in the distribution of the specific reasons for failure to geocode among cases and controls.

To identify agricultural use fields proximate to birth residences, we acquired digital orthophoto quadrangle (DOQ) data from the Texas Natural Resource Information System (TNRIS) for each study subject (TNRIS 2007). A DOQ is a digital mapping image of an aerial photograph in which image distortion caused by perspective, camera tilt and terrain relief are removed. These 1-meter ground resolution images cover an area 3.75 minutes of latitude by 3.75 minutes of longitude and were flown during leaf off periods between 1995 and 1997. Although some of the images were black and white, the majority were color infrared. The DOQs were used to visually determine agricultural fields based on tone and color, geometry of objects (size and shape), spatial arrangement of tonal boundaries (texture and pattern), and context of objects. Field boundaries of all identified agricultural fields were digitized to allow for selection of fields within a 1000 meter exposure buffer around the birth residence of the study subjects. The number and area of agricultural fields within each exposure buffer was extracted for use in statistical analyses.

\section{Statistical analysis}

The Field Mass Index (FMI) was created to incorporate both the area of any agricultural field within the designated buffer around the residence and the distance to each field from the residence $\left(\mathrm{FMI}=\right.$ area/distance $\left.{ }^{2}\right)$. Where there were multiple fields within the buffer zone, the FMIs for each field were summed. Study subjects with an FMI equal to zero constituted the unexposed comparison group. We used the median of the distribution of FMI values to divide probable exposure into low (FMI < 0.54) and high (FMI $\geq 0.54)$ categories. We also evaluated total acreage within the buffer and average distance of the field(s) from the resident separately.

Cancer diagnoses were grouped according to the International Classification of Childhood Cancers (ICCC) system (Birch and Marsden, 1987). Multivariate logistic regression models were used to estimate odds ratios (OR) and 95 percent confidence intervals (CI). Although data on potential confounders was captured from the birth certificates for both cases and controls, many records were missing confounder information. Among total study subjects, $68.5 \%$ were missing valid values for maternal and paternal occupation. A total of $31.6 \%$ of subjects were missing information regarding maternal cigarette and alcohol use, and $31.5 \%$ were missing information regarding parental education. Of children for whom maternal alcohol and cigarette use was available, only $0.9 \%$ had a positive history of maternal alcohol use and only $5.5 \%$ had a positive history of maternal cigarette use. Therefore, maternal and paternal occupation and maternal alcohol and cigarette use were not included as possible confounders in the statistical modeling. Child's age at diagnosis, gender, race/ethnicity, maternal age, and birth weight were determined to be sufficiently complete to be included in analyses as potential confounders. Neither birth weight nor maternal age changed the magnitude or precision of the point estimates for total cancers and the major ICCC cancer groups, so these variables were dropped from the final models. In a related analysis using additional years of study data from the parent casecontrol study, paternal education was evaluated (as a surrogate for socio-economic status) and was not found to be an apparent confounder for total childhood cancers or for the more common cancer subtypes (Walker et al., 2007). Hence, final models were adjusted for birth date, gender and race/ethnicity.

In addition, because the method of matching for cases and controls resulted in approximately one-to-one matching rather than a true frequency match, we compared results from both conditional and unconditional logistic regression. The point estimates generated by both 
approaches were equivalent and thus the odds ratios and confidence intervals presented in this paper were estimated using unconditional logistic regression. All data analyses were performed using the SAS software package, version 9.1.

\section{Results}

Cases and controls were similar demographically (Table 1 ). There were slightly more male than female study subjects. Of the total study subjects, $46 \%$ were non-Hispanic white children and $39 \%$ were Hispanic children. The birth residences of approximately $17 \%$ of study subjects had agricultural use land within a 1,000 meter circular buffer.

Leukemia was the most common cancer type, accounting for $34.1 \%$ of the total cancer cases; the majority of leukemias were lymphoid leukemias (76.6\% of total leukemias) (Table 2). Central nervous system (CNS) tumors comprised $19.0 \%$ of total cancer cases, with astrocytoma being the most common brain tumor diagnosed in these children (33.4\% of total CNS). Of the sympathetic nervous system tumors ( $12.4 \%$ of total cancers), all but three were neuroblastomas. The remaining ICCC groups each accounted for less than $8.0 \%$ of the total cases, with malignant bone tumors being the least common specific cancer diagnosis (1.0\% of total cases).

For total cancers and the majority of specific cancers, both groups and subtypes, there was no association with proximity of birth residence to agricultural use land (Table 3). There were a few cancers, however, for which there was some evidence of increased risk with exposure. When defining exposure as birth residence located within 1000 meters of agricultural use land, non-Hodgkin lymphoma (NHL) (OR=1.5, 95\% CI: 0.6, 3.7), Burkitt lymphoma (OR = 1.5, $95 \%$ CI: 0.4, 5.5) and other gliomas (OR=1.6, 95\% CI: 0.7, 3.2) had elevated ORs; however, none of the point estimates were statistically significant. There was an overall pattern of elevated ORs for germ-cell tumors whether exposure was defined by the $1000 \mathrm{~m}$ buffer or by field mass index (FMI), but these point estimates were not statistically significant and did not exhibit a dose response. The category of other gliomas also had increased ORs for the FMI exposure definition $\left(\mathrm{OR}_{\text {low }}=1.7 ; 95 \%\right.$ CI: $0.7,4.2 ; \mathrm{OR}_{\text {high }}=1.3 ; 95 \%$ CI: $\left.0.5,3.9\right)$, but these also were not statistically significant and did not support a dose response to the exposure. The increased risk seen for Burkitt lymphoma with the broader exposure definition was also seen for the FMI exposure definition $\left(\mathrm{OR}_{\text {low }}=3.1 ; 95 \% \mathrm{CI}\right.$ : $0.8,11.8$; no exposed cases for high FMI). There was also an increased OR for NHL when assessed using FMI, but only for the low exposure category $\left(\mathrm{OR}_{\text {low }}=2.2 ; 95 \%\right.$ CI $\left.0.8,6.0\right)$.

For total cancers and most leading cancer types, there was no increased risk apparent with exposure defined as either total acreage of agricultural use land within a 1000 meter buffer around the birth residence or average distance of the residence from that land (tables 4 and 5). There was some increased risk seen with both exposure definitions for NHL, but none were statistically significant and there was no clear increase with increasing acreage (i.e "dose") response $\left(\mathrm{OR}_{\text {low acreage }}=2.4 ; 95 \% \mathrm{CI} 0.8,7.2 ; \mathrm{OR}_{\text {high distance }}=1.8 ; 95 \% \mathrm{CI} 0.5,6.1\right)$. Burkitt lymphoma showed consistently elevated ORs for both acreage and distance, but all point estimates were based on very few cases and were imprecise.

Among central nervous system tumors (CNS), ependymomas and astrocytomas showed increased risk associated only with the highest acreage and lowest distance categories $\left(\mathrm{OR}_{\text {high acreage }}=1.7 ; 95 \% \mathrm{CI} 0.7,4.4, \mathrm{OR}_{\text {low distance }}=1.6 ; 95 \% \mathrm{CI} 0.6,4.1\right.$ and $\mathrm{OR}_{\text {high acreage }}$ $=1.3 ; 95 \% \mathrm{CI} 0.6,2.7, \mathrm{OR}_{\text {low distance }}=1.5 ; 95 \% \mathrm{CI} 0.8,3.0$, respectively). The other gliomas category had a pattern of increased risk for all categories except low average distance. All these CNS tumor point estimates were based on few cases and were not statistically significant. 
Several types of germ cell tumors had substantially elevated risk with both total acreage and average distance. Intracranial and intraspinal germ cell tumors had increased risk for both categories: $\mathrm{OR}_{\text {low acreage }}=6.3(95 \% \mathrm{CI} 1.1,34.8)$ and $\mathrm{OR}_{\text {high acreage }}=3.7(95 \% \mathrm{CI} 0.4,32.9)$; $\mathrm{OR}_{\text {medium distance }}=6.8(95 \% \mathrm{CI} 1.3,36.6)$ and $\mathrm{OR}_{\text {high distance }}=3.0(95 \% \mathrm{CI} 0.3,26.9)$. Gonadal germ cell tumors had increased risk for the low and high categories of both acreage and distance $\left(\mathrm{OR}_{\text {low acreage }}=2.0(95 \% \mathrm{CI} 0.7,6.1)\right.$ and $\mathrm{OR}_{\text {high acreage }}=2.6(95 \% \mathrm{CI} 0.8,7.7$;

$\mathrm{OR}_{\text {low distance }}=1.7(95 \% \mathrm{CI} 0.5,5.9)$ and $\mathrm{OR}_{\text {high distance }}=2.1(95 \%$ CI $0.7,6.4)$. All germ cell tumor ORs were based on very few exposed cases, resulting in imprecise and mostly statistically non-significant estimates.

\section{Discussion}

We found no evidence of elevated risk associated with residential proximity at birth to agricultural use land for most childhood cancers. There was an overall pattern of increased risk for germ cell tumors but the odds ratios were based on few numbers of exposed cases. There was also some indication of increased risk for NHL and Burkitt lymphoma, but point estimates were imprecise and not statistically significant.

Most epidemiological studies of pesticide exposure have not had sufficient numbers of germ cell tumors in the study population to evaluate risk. Of three reports on germ cell tumors based on participants in the Children's Oncology Group (COG), two evaluated parental occupational exposure, with one reporting in general no association between parental exposure to pesticides in the workplace (Chen et al., 2005) and the other finding an approximately two-fold nonsignificantly increased risk for either maternal or paternal self-reported occupational exposure to insecticides or herbicides (Shu et al., 1995). The third COG report focused on self-reported residential pesticide use and found no strong association with development of germ cell tumors in children (Chen et al., 2006).

For both NHL and Burkitt lymphoma, we found non-significant increases in risk which varied slightly according to exposure definition. Daniels et al. (1997) found that farm residence, but not paternal or maternal occupational exposure, was associated with NHL in their review of published epidemiological studies of pesticides and childhood cancer. In a similar review, Zahm and Ward (1998) concluded that there was some support for an association of childhood NHL and pesticide exposures, but noted that the results of most studies were based on small numbers of exposed cases. In updated reviews, Jurewicz and Hanke (2006), and Infante-Rivard and Weichenthal (2007) report on four additional studies, three of which found an increased risk for some measure of pesticide exposure and NHL and/or all lymphomas. Nasterlack (2007), in a review of studies conducted since 1998, noted that in contrast to case-control studies, cohort studies consistently showed no increased risk for NHL, but did suggest an elevated risk for Hodgkin's disease. The studies evaluated in all these reviews generally measured either parental occupational exposure (e.g. farming occupations or pesticide applicators) or household use of pesticides (e.g. residential pesticide services). In the only study to specifically evaluate residential exposures to agricultural pesticides, Reynolds et al. (2005b) found modest, non-significant increased risk for Hodgkin disease, but not NHL.

Epidemiological data to evaluate possible risk of Burkitt lymphoma resulting from pesticide exposures is quite scarce. Flower et al. (2004) reported an elevated SIR of 2.67 (95\% CI 0.37, 19.0) for Burkitt lymphoma among children of private pesticide applicators (i.e. farmers), but this was based on only two cases. In a large study from the Children's Cancer Group (a precursor to the $\mathrm{COG}$ ) that was of sufficient size to address risk of Burkitt lymphoma associated with pesticides, Buckley et al. (2000) reported a statistically significant 7-fold increase in risk. For this study, pesticide exposure was measured by a composite score based on relatively nonspecific questions about household insect and garden sprays, use of professional 
exterminators, and possible occupation exposures. In studies evaluating metabolites of organohalogen compounds and dioxins and dibenzofurans (components of common herbicides) and adult NHL, Hardell et al. (2001a, 2001b) reported a possible interactive effect between some pesticides and pesticide contaminants and Epstein-Barr antigen positive status. As Epstein-Barr virus is a recognized risk factor for Burkitt lymphoma, this finding of a possible increased risk of lymphomas among virus positive individuals exposed to common pesticides components may be of particular import when interpreting our results.

Our study failed to find a consistent relationship between agricultural pesticides and leukemias or, with the exception of other gliomas, CNS tumors. As recent reviews noted, leukemias (primarily ALL) and CNS tumors have often been associated with occupational and/or home use of pesticides in epidemiological studies (Daniels et al., 1997; Zahm and Ward, 1998; Jurewicz and Hanke, 2006; Infante-Rivard and Weichenthal, 2007; Nasterlack, 2007). Daniels et al. (1997) noted that farm residence during pregnancy or childhood increased risk for primitive neuroectodermal and non-astrocytic neuroepithelial tumors, but not astrocytic gliomas, and in general did not result in increased risk of leukemias. In the only studies specifically evaluating agricultural pesticide use and childhood cancers, and so the most similar to ours, Reynolds et al. (2005a, 2005b) reported no clear risk patterns for leukemias or CNS tumors. In a related ecological study that investigated risk for specific agricultural pesticides used in the California population, Reynolds et al. (2002) reported no consistent associations between residence in areas of high agricultural pesticide use and either total childhood leukemias or gliomas.

Our study differs from most published studies of risk of childhood cancer and pesticide exposures in several ways that might affect comparisons of results. The majority of these studies have assigned pesticide exposure status based on parental occupational history and/or household use. Our focus was on agricultural pesticides and, while there is some overlap, these may represent a quite different array of chemical agents. In addition, the dose of any pesticide that would be received due to off-target drift is likely to be less than that of a directed home application. It is also unclear as to what the most biologically pertinent window of exposure is for pesticides and risk of childhood cancers; it may even differ by cancer type. Our a priori hypothesis was that transplacental exposure to the fetus during pregnancy was the most relevant period, however, other studies have varied in the exposure window evaluated, ranging from conception, during pregnancy and through childhood up to the time of diagnosis in cases.

In addition to these study differences, there are several methodological issues that need to be considered when interpreting our results. As there is no registry of agricultural pesticide applications in Texas, we used the surrogate of residential proximity to assign probable pesticide exposure. Several studies have reported that, in agricultural communities, residues in house dust and yard soil of the most common category of agricultural pesticides, organophosphates, are inversely associated with distance from treated fields (Simcox et al., 1995; Loewenherz et al., 1997; Lu et al., 2000). Lu et al. (2000) found that children living near treated orchards had statistically significantly higher levels of pesticide metabolites in their urine as compared to children living more distant, and Weppner et al. (2006) confirmed pesticide residues on playground equipment, toys and childrens' hands after aerial spraying of surrounding potato, corn and wheat fields. In a study of adult NHL, homes within 750 meters of crop fields had concentrations of agricultural herbicides more than 4-fold higher than those with no crops (Ward et al., 2000). As these studies indicate, there is a clear risk of accumulation of agricultural pesticides in and around homes located in close proximity to crop fields. It is a limitation of the study, however, that we did not have data on specific crops grown in the fields identified by our GIS methodology. Cropping information would have allowed us to investigate specific categories of agricultural pesticides based on recommendations made by the Texas Department of Agriculture and the Texas AgriLife Extension Service to growers of specific 
crops as to pesticides and timing of pesticide applications to use for maximum crop growth in different areas of the state. Crop data would have made it possible to refine timing of pesticide exposures according to planting and harvesting cycles for each crop, and thus would have allowed us to evaluate specific windows of exposure during pregnancy.

Although our large sample size allowed us to evaluate risk for cancers other than leukemia and CNS tumors, small numbers of exposed cases resulted in imprecise estimates for many of the rarer cancers, and appropriate caution should be used when interpreting these results. Because of the population and records based nature of our data collection, recall and selection bias are not a concern in this case-control study. While there is likely to be misclassification of the exposure, there is no obvious reason to believe it would be differential with regard to case status. We had only limited information on confounders, but so little is known about the etiology of most childhood cancers that confounding is unlikely to explain the patterns in our data. It is also worth mentioning that in our data set many cancer types have only a few exposed cases (see Table 3), thus the results for those cases may not replicate well given a larger data set. For those circumstances, our analysis should be considered exploratory and provides a resource for further study.

As far as we are aware, this study is one of only a few to specifically investigate risk of childhood cancers associated with residential proximity to agricultural use land (Reynolds 2005a, 2005b). To date, epidemiological studies of pesticide exposures and childhood cancers have not primarily evaluated agricultural pesticides, but rather have focused on residential pesticide use or occupational exposures of parents (Daniels et al., 1997; Zahm and Ward, 1998; Jurewicz and Hanke, 2006; Infante-Rivard and Weichenthal, 2007; Nasterlack, 2007). The bulk of pesticide use in the U.S., however, is for agricultural rather than residential application. Many non-farming residents of small towns in rural settings live in areas bordered by agricultural use land, with town residents possibly less aware of their true proximity to crop land. While it is likely that the most direct effect of agricultural practices is among farmers, agricultural workers, and their families, there is clear potential as well for an impact on the surrounding communities.

Epidemiological studies of this exposure will continue to be a challenge, as questionnaires are unlikely to be accurate and biomarkers are not yet readily available or feasible for large scale studies. There is great potential to improve the exposure assessment for agricultural pesticides through GIS-based methodology (Ward and Wartenberg, 2006). The incorporation of validated drift modeling, specific crop information and residential history would allow for more complete assessment of timing of exposure. GIS methods have been demonstrated to be a cost-effective tool with which to reliably reconstruct an exposure history for thousands of study subjects scattered across hundreds of miles and several decades (Ward et al., 2000, 2006; Nuckols et al., 2007). This approach may make it possible to more accurately assess the risk to children in communities throughout the U.S. that are impacted by crop production activities through simple physical proximity.

\section{Acknowledgements}

This research was supported by National Institutes of Health National Cancer Institute grant R01 CA92670.

\section{References}

Baker LW, Fitzell DL, Seiber JN, Parker TR, Shibamoto T, Poore MW, Longley KE, Tomlin RP, Propper R, Duncan DW. Ambient air concentrations of pesticides in California. Environ Sci Technol 1996;30 (4):1365-1368.

Birch JM, Marsden HB. A classification scheme for childhood cancer. Int J Cancer 1987;40(5):620-4. [PubMed: 3679589] 
Buckley JD, Meadows AT, Kadin ME, Le Beau MM, Siegel S, Robison LL. Pesticide exposures in children with non-Hodgkin lymphoma. Cancer 2000;89(11):2315-21. [PubMed: 11147603]

Centers for Disease Control and Prevention. Third National Report on Human Exposure to Environmental Chemicals. Atlanta (GA): Centers for Disease Control and Prevention; 2005. (http://www.cdc.gov/exposurereport/report.htm)

Chen Z, Stewart PA, Davies S, Giller R, Krailo M, Davis M, Robison L, Shu X-O. Parental occupational exposure to pesticides and childhood germ-cell tumors. Am J Epidemiol 2005;162(9):858-867. [PubMed: 16192347]

Chen Z, Robison L, Giller R, Krailo M, Davis M, Davies S, Shu XO. Environmental exposure to residential pesticides, chemicals, dusts, fumes, and metals, and risk of childhood germ cell tumors. Int J Hyg Environ Health 2006;209(1):31-40. [PubMed: 16373200]

Daniels JL, Olshan AF, Savitz DA. Pesticides and childhood cancers. Environ Health Perspect 1997;105 (10):1068-77. [PubMed: 9349828]

Dich J, Zahm SH, Hanberg A, Adami H-O. Pesticides and cancer. Cancer Causes and Control 1997;8(3): 420-443. [PubMed: 9498903]

Fenske RA, Lu C, Barr D, Needham L. Children's exposure to chlorpyrifos and parathion in an agricultural community in central Washington State. Environ Health Perspect 2002;110(5):549-53. [PubMed: 12003762]

Flower KB, Hoppin JA, Lynch CF, Blair A, Knott C, Shore DL, Sandler DP. Cancer risk and parental pesticide application in children of agricultural health study participants. Environ Health Perspect 2004;112(5):631-5. [PubMed: 15064173]

Hardell L, Eriksson M, Lindstrom G, Van Bavel B, Linde A, Carlberg M, Liljegren G. Case-control study on concentrations of organohalogen compounds and titers of antibodies to Epstein-Barr virus antigens in the etiology of non-Hodgkin lymphoma. Leuk Lymphoma 2001a;42(4):619-29. [PubMed: 11697490]

Hardell L, Lindstrom G, van Bavel B, Hardell K, Linde A, Carlberg M, Liljegren G. Adipose tissue concentrations of dioxins and dibenzofurans, titers of antibodies to Epstein-Barr virus early antigen and the risk for non-Hodgkin lymphoma. Environ Res 2001b;87(2):99-107. [PubMed: 11683593]

Infante-Rivard C, Weichenthal S. Pesticides and childhood cancer: an update of Zahm and Ward's 1998 review. J Tox Environ Health 2007;10:81-99.

Jurewicz J, Hanke W. Exposure to pesticides and childhood cancer risk: has there been any progress in epidemiological studies? Int J Occup Med Environ Health 2006;19(3):152-69. [PubMed: 17252666]

Koch D, Lu C, Fisker-Andersen J, Jolley L, Fenske RA. Temporal association of children's pesticide exposure and agricultural spraying: report of a longitudinal biological monitoring study. Environ Health Perspect 2002;110(8):829-33. [PubMed: 12153767]

Loewenherz C, Fenske RA, Simcox NJ, Bellamy G, Kalman D. Biological monitoring of organophosphorus pesticide exposure among children of agricultural workers in central Washington State. Environ Health Perspect 1997;105(12):1344-53. [PubMed: 9405329]

Lu C, Fenske FA, Simcox NJ, Kalman D. Pesticide exposure of children in an agricultural community: evidence of household proximity to farmland and take home exposure pathways. Environ Res 2000;84(3):290-302. [PubMed: 11097803]

Lu C, Knutson DE, Fisker-Andersen J, Fenske RA. Biological monitoring survey of organophosphorus pesticide exposure among pre-school children in the Seattle metropolitan area. Environ Health Perspect 2001;109(3):299-303. [PubMed: 11333193]

Nasterlack M. Pesticides and childhood cancer: an update. Int J Hyg Environ Health 2007;210:645-657. [PubMed: 17434797]

Nuckols JR, Gunier RB, Riggs P, Miller R, Reynolds P, Ward MH. Linkage of the California Pesticide Use Reporting Database with spatial land use data for exposure assessment. Environ Health Perspect 2007;115(5):684-9. [PubMed: 17520053]

Reynolds P, Von Behren J, Gunier RB, Goldberg DE, Hertz A, Harnly ME. Childhood cancer and agricultural pesticide use: an ecologic study in California. Environ Health Perspect 2002;110(3):31924. [PubMed: 11882484]

Reynolds P, Von Behren J, Gunier RB, Goldberg DE, Harnly M, Hertz A. Agricultural pesticide use and childhood cancer in California. Epidemiology 2005a;16(1):93-100. [PubMed: 15613951] 
Reynolds P, Von Behren J, Gunier R, Goldberg DE, Hertz A. Agricultural pesticides and lymphoproliferative childhood cancer in California. Scand J Work Environ Health 2005b;31(Suppl 1):46-54. [PubMed: 16190149]

Shalat SL, Donnelly KC, Freeman NC, Calvin JA, Ramesh S, Jimenez M, Black K, Coutinho C, Needham LL, Barr DB, Ramirez J. Nondietary ingestion of pesticides by children in an agricultural community on the US/Mexico border: preliminary results. J Expo Anal Environ Epidemiol 2003;13(1):42-50. [PubMed: 12595883]

Shu XO, Nesbit ME, Buckley JD, Krailo MD, Robinson LL. An exploratory analysis of risk factors for childhood malignant germ-cell tumors: report from the Childrens Cancer Group (Canada, United States). Cancer Causes Control 1995;6(3):187-98. [PubMed: 7612798]

Simcox NJ, Fenske RA, Wolz SA, Lee IC, Kalman DA. Pesticides in household dust and soil: exposure pathways for children of agricultural families. Environ Health Perspect 1995;103(12):1126-34. [PubMed: 8747019]

Texas Natural Resources Information System (TNRIS). National Agriculture Imagery Program (NAIP) and DOQQ Imagery. Austin, TX: Texas Water Development Board; 2007. (http://www.tnris.org/StratMap.aspx?layer=126)

Tiefenbacher JP. Mapping the pesticide driftscape: theoretical patterns of the drift hazard. Geographical \& Environmental Modeling 1998;2(1):83-101.

United States Department of Agriculture. The 1997 Census of Agriculture Volume 1: Geographic Area Series. United States Department of Agriculture: National Agricultural Statistics Service, ; 1997. (http://www.nass.usda.gov/census/census97/county/farms/index.htm)

United States Environmental Protection Agency. Chemicals evaluated for carcinogenic potential. Vol. 19. Washington, DC: United States Environmental Protection Agency: Science Information Management Branch, Health Effects Division, Office of Pesticide Programs; Jul. 2004

van den Berg F, Kubiak R, Benjey WG, Majewski MS, Yates SR, Reeves G, Smelt JH, van der Linden AMA. Emission of pesticides into the air. Water, Air, and Soil Pollution 1999;115:195-218.

Walker KM, Carozza S, Cooper S, Elgethun K. Childhood cancer in Texas counties with moderate to intense agricultural activity. J Agric Saf Health 2007;13(1):9-24. [PubMed: 17370910]

Ward MH, Nuckols JR, Weigel SJ, Maxwell SK, Cantor KP, Miller RS. Identifying populations potentially exposed to agricultural pesticides using remote sensing and a Geographic Information System. Environ Health Perspect 2000;108(1):5-12. [PubMed: 10622770]

Ward MH, Lubin J, Giglierano J, Colt JS, Wolter C, Bekiroglu N, Camann D, Hartge P, Nuckols JR. Proximity to crops and residential exposure to agricultural herbicides in Iowa. Environ Health Perspect 2006;114(6):893-7. [PubMed: 16759991]

Ward MH, Wartenberg D. Invited commentary: on the road to improved exposure assessment using geographic information systems. Am J Epidemiol 2006;164(3):208-11. [PubMed: 16707652]

Weppner S, Elgethun K, Lu C, Hebert V, Yost MG, Fenske RA. The Washington aerial spray drift study: children's exposure to methamidophos in an agricultural community following fixed-wing aircraft applications. J Expo Sci Environ Epidemiol 2006;16(5):387-96. [PubMed: 16249796]

Zahm SH, Ward MH. Pesticides and childhood cancer. Environ Health Perspect 1998;106(Suppl 3):893908. [PubMed: 9646054] 
Table 1

Descriptive characteristics of study subjects. Texas, 1990-1998.

\begin{tabular}{|c|c|c|c|c|}
\hline Characteristic & Cases & $(\%)$ & Controls & $(\%)$ \\
\hline Total & 1778 & & 1802 & \\
\hline \multicolumn{5}{|l|}{ Gender } \\
\hline males & 1015 & 57.1 & 1009 & 56.0 \\
\hline females & 763 & 42.9 & 793 & 44.0 \\
\hline \multicolumn{5}{|l|}{ Race/ethnicity } \\
\hline Non-Hispanic white & 867 & 48.8 & 792 & 44.0 \\
\hline Non-Hispanic black & 194 & 10.9 & 241 & 13.4 \\
\hline Hispanic & 673 & 37.9 & 710 & 39.4 \\
\hline Other & 44 & 2.5 & 59 & 3.3 \\
\hline Exposed $^{*}$ & 299 & 16.8 & 317 & 17.6 \\
\hline
\end{tabular}

*xposed $=$ any agricultural use land within $1000 \mathrm{~m}$ of birth residence 
Table 2

Distribution of childhood cancer cases by ICCC major groups and selected subgroups. Texas, 1990-1998.

\begin{tabular}{|c|c|c|}
\hline ICCC cancer groups & Total & $\%$ * \\
\hline All cancers & 1778 & 100.0 \\
\hline I Leukemia & 606 & 34.1 \\
\hline I(a) Lymphoid leukemia & 464 & 76.6 \\
\hline II Lymphoma and reticuloendothelial neoplasms & 70 & 3.9 \\
\hline II(a) Hodgkin lymphoma & 9 & 12.9 \\
\hline II(b) Non-Hodgkin lymphoma & 27 & 38.6 \\
\hline II(c) Burkitt lymphoma & 13 & 18.6 \\
\hline III CNS and misc intracranial and intraspinal neoplasms & 338 & 19.0 \\
\hline III(a) Ependymoma & 54 & 16.0 \\
\hline III(b) Astrocytoma & 113 & 33.4 \\
\hline III(c) Primitive neuroectodermal tumors & 74 & 21.9 \\
\hline III(d) Other gliomas & 42 & 12.4 \\
\hline IV Sympathetic nervous system tumors & 221 & 12.4 \\
\hline IV(a) Neuroblastoma and ganglioneuroblastoma & 218 & 98.6 \\
\hline V Retinoblastoma & 109 & 6.1 \\
\hline VI Renal tumors & 139 & 7.8 \\
\hline VI(a) Wilms tumor, rhabdoid and clear cell sarcoma & 138 & 99.3 \\
\hline VII Hepatic tumors & 51 & 2.9 \\
\hline VII(a) Hepatoblastoma & 46 & 90.2 \\
\hline VIII Malignant bone tumors & 18 & 1.0 \\
\hline IX Soft-tissue sarcomas & 114 & 6.4 \\
\hline IX(a) Rhabdomyosarcoma and embryonal sarcoma & 65 & 57.0 \\
\hline IX(b) Fibrosarcoma, neurofibrosar and oth fibromatous neop & 19 & 16.7 \\
\hline X Germ-cell, trophoblastic and other gonadal neoplasms & 65 & 3.7 \\
\hline $\mathrm{X}$ (a) Intracranial and intraspinal germ-cell tumors & 8 & 12.3 \\
\hline $\mathrm{X}$ (b) Other and unspecified non-gonadal germ-cell tumors & 22 & 33.8 \\
\hline $\mathrm{X}(\mathrm{c})$ Gonadal germ-cell tumors & 34 & 52.3 \\
\hline XI Carcinomas and other malignant epithelial neoplasms & 15 & 0.8 \\
\hline XII Other and unspecified malignant neoplasms & 14 & 0.8 \\
\hline
\end{tabular}

* Number in bold represents percent of total cancer cases, italicized numbers indicate percent of individual ICCC group. 


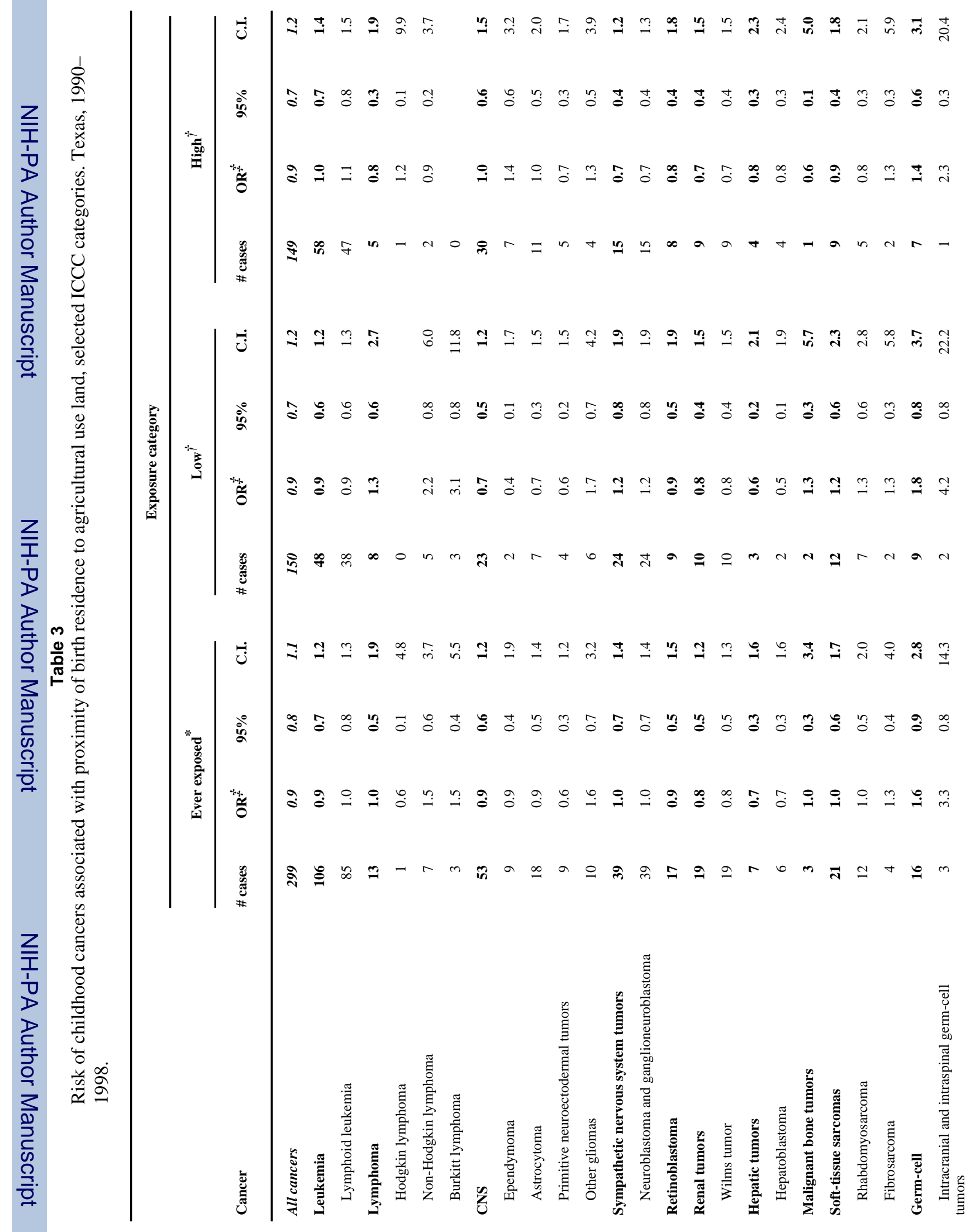

Int J Hyg Environ Health. Author manuscript; available in PMC 2010 March 1. 


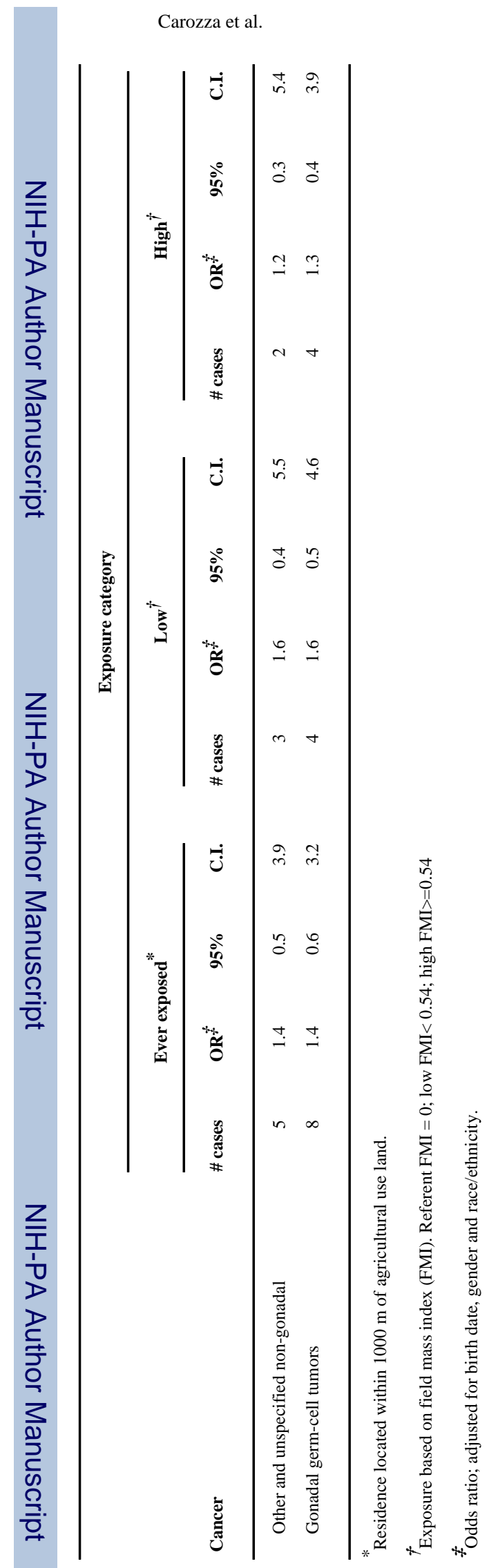

Int J Hyg Environ Health. Author manuscript; available in PMC 2010 March 1. 


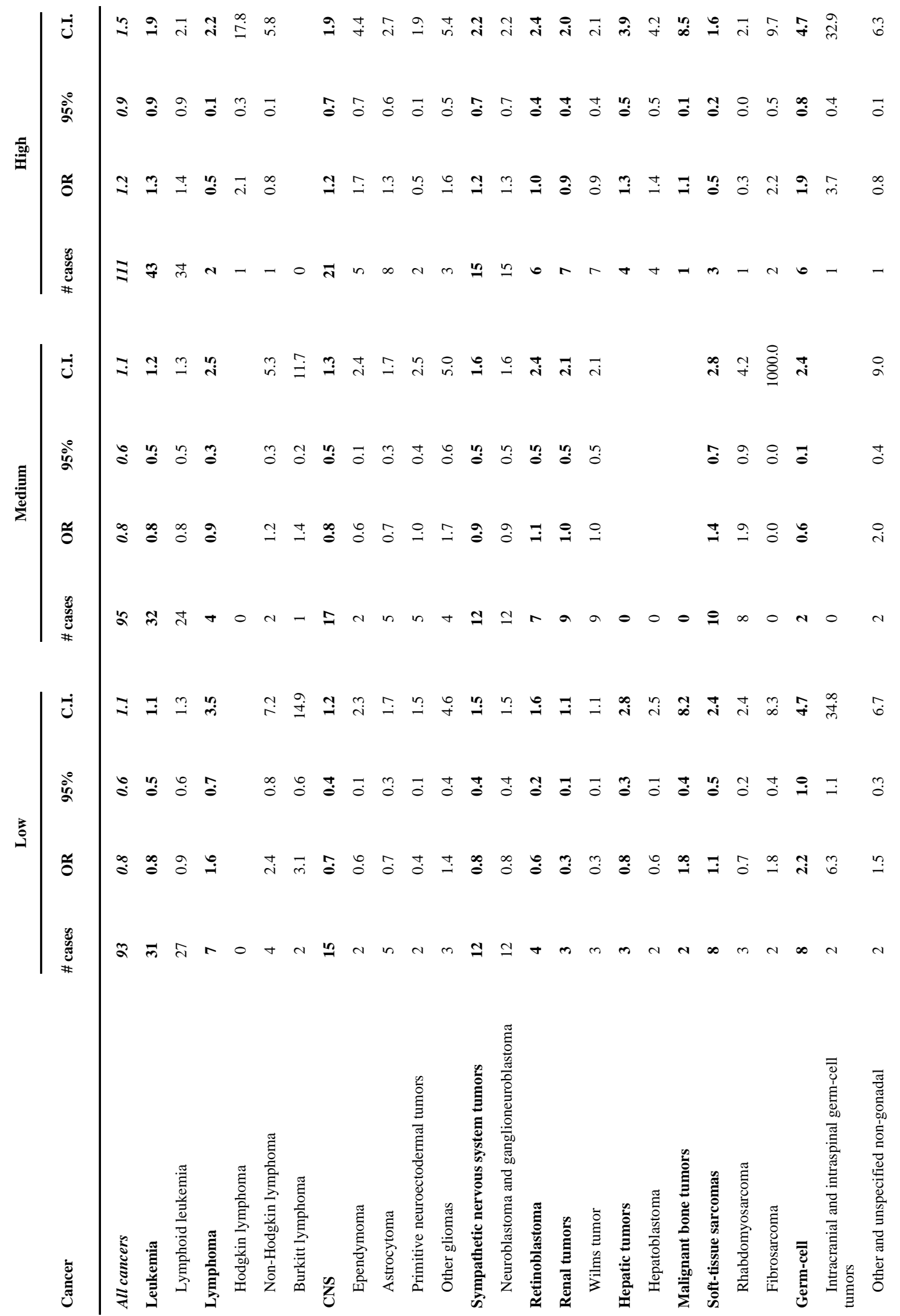




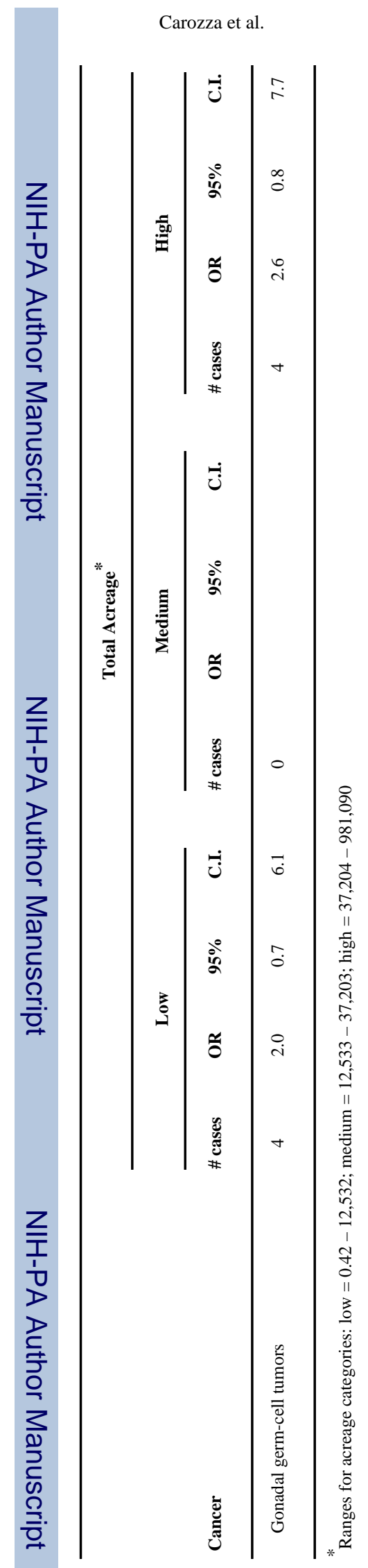

Page 15 


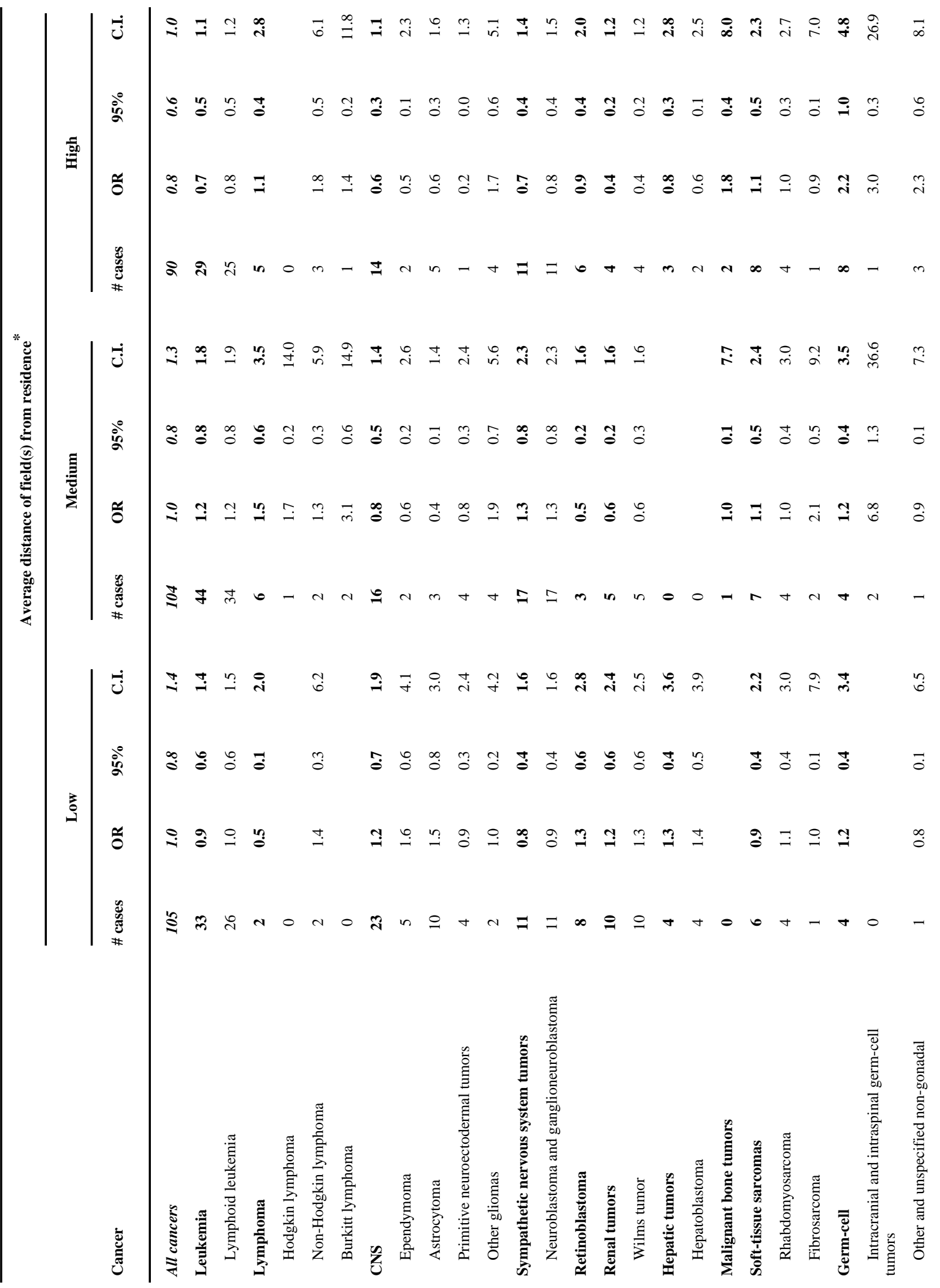




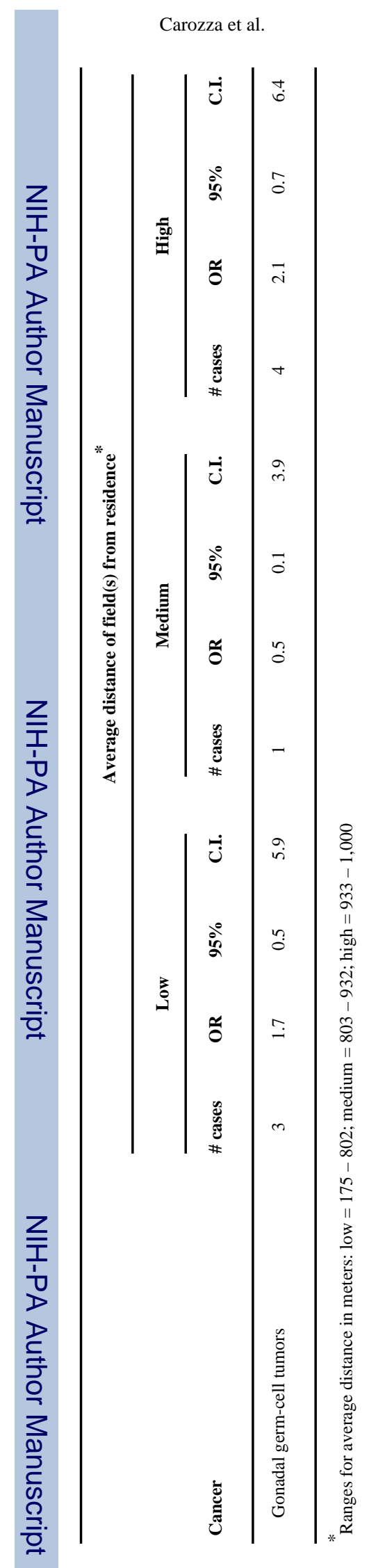

Page 17 